\title{
Blood Pressure and Cardiorenal Responses to Antihypertensive Therapy in Obese Women
}

\begin{abstract}
Objective: Blood pressure(BP) and target organ responses to antihypertensive drugs are not well established in hypertensive obese patients. This study is aimed at evaluating the effects of obesity and adiposity distribution patterns on these responses. Methods: 49 hypertensive obese women were designated to different groups according to waist to hip ratio measurements - 37 with troncular and 12 with peripheral obesity. Patients were treated for 24-weeks on a stepwise regimen with cilazapril alone or a cilazapril/hydrochlorothiazide/amlodipine combination therapy to achieve a BP lower than $140 / 90 \mathrm{mmHg}$. Ambulatory blood pressure monitoring (ABPM), echocardiography, and albuminuria were assessed before and after the intervention. Results: After 24 weeks, weight loss was less than $2 \%$ in both groups. ABPM targets were achieved in $81.5 \%$ of patients upon a combination of $2(26.5 \%)$ or $3(55.1 \%)$ drugs. Similar reductions in daytime-SBP/DBP: -22.5/-14.1(troncular obesity) / -23.6/-14.9mmHg (peripheral obesity) were obtained. Decrease in nocturnal-SBP was greater in troncular obesity patients. Upon BP control, microalbuminuria was markedly decreased, while only slight decrease in left ventricular mass was observed for both groups. Conclusions: In the absence of weight loss, most patients required combined antihypertensive therapy to control their BP, regardless of their body fat distribution pattern. Optimal target $\mathrm{BP}$ and normal albuminuria were achieved in the group as a whole and in both obese patient groups, while benefits to cardiac structure were of a smaller magnitude. (Arq Bras Endocrinol Metab 2008;52/1:65-75)
\end{abstract}

Keywords: Hypertension; Obesity; Body fat distribution; Antihypertensive therapy; Echocardiography; Albuminuria.

\section{RESUMO}

\section{Respostas Pressórica e Cardiorrenal à Terapia Anti-hipertensiva em Mulheres Obesas.}

As respostas pressórica e de órgãos-alvo mediante o tratamento anti-hipertensivo medicamentoso, não estão bem estabelecidas em pacientes obesos hipertensos. $O$ presente estudo tem por objetivo avaliar as repercussões da obesidade e da distribuição de gordura corporal sobre estas respostas. Métodos: Foram avaliadas 49 mulheres obesas hipertensas, separadas em subgrupos com distribuição troncular $(n=37)$ e periférica $(n=12)$ de gordura, de acordo com a distribuição cintura/quadril. As pacientes foram tratadas por 24 semanas com um regime anti-hipertensivo escalonado, iniciando-se com cilazapril e adicionando-se na seqüência, hidroclortiazida e amlodipina, com alvo pressórico inferior a 140 × $90 \mathrm{mmHg}$. Foram realizados MAPA, ecocardiograma e microalbuminuria antes e após o tratamento. Resultados: Depois de 24 semanas observou-se perda de peso inferior a $2 \%$ em ambos os subgrupos. $\mathrm{O}$ controle pressórico à MAPA pode ser observado em $81,5 \%$ das pacientes mediante a combinação de duas $(26,5 \%)$ ou três $(55,1 \%)$ drogas. Foram obtidas redu- artigo original

\author{
Eduardo Cantoni Rosa \\ MARIA TEREZA ZANELLA \\ NÁrCIa ElISA BELLUCCI KoHLMANN \\ SANDRA Roberta GouveIa Ferreira \\ FRIDA LIANE PLAVNIK \\ Artur Beltrame Ribeiro \\ OsValdo KOHLMANN $J_{R}$.
}

Hypertension and

Cardiovascular Metabology

Center, Kidney and Hypertension Hospital, Divisions of Nephrology and Endocrinology - São Paulo Federal University, São Paulo, SP, Brazil.

Recebido em 27/03/2007

Aceito em 03/10/2007 
ções similares nas medidas de PAS/PAD diurnas: -22,5/-14,1 (obesas tronculares)/-23,6/-14,9 $\mathrm{mmHg}$ (obesas periféricas), enquanto se observou nas obesas tronculares redução maior na PAS noturna. Mediante o controle pressórico, houve redução acentuada da microalbuminúria nos dois subgrupos. Por outro lado, observou-se em ambos, apenas discreta redução na massa ventricular. Conclusões: $\mathrm{Na}$ ausência de perda significativa de peso, e independentemente da distribuição de gordura corporal, a maioria das pacientes obesas necessitou terapia anti-hipertensiva combinada a fim de obter controle pressórico. Em ambos os subgrupos foram alcançados níveis adequados de pressão arterial e redução satisfatória da microalbuminúria, ao passo que os benefícios para a regressão estrutural cardíaca foram menores. (Arq Bras Endocrinol Metab 2008;52/ 1:65-75)

Descritores: Hipertensão; Obesidade; Distribuição de gordura corporal; Terapia anti-hipertensiva; Ecocardiograma; Microalbuminúria.

\section{INTRODUCTION}

$\mathrm{O}$ BESITY IS A PREVALENT DISEASE in modern society and has a negative impact on health. Visceral obesity has claimed more attention due to its association with cardiovascular risk (1), especially attributed to diabetes, dyslipidemia and hypertension $(2,3)$.

Indeed, available data show that neurohumoral, hemodynamic and inflammatory disorders, as well as target organ injuries in obese, are most commonly associated with visceral than with peripheral adiposity or total body fat (4-9).

Most studies that evaluate treatment of hypertension in obesity, as well as target organ responses, particularly the cardiorenal axis responses, regard weight loss, which has proven to be an effective approach (10-14). However, since weight loss maintenance is somewhat difficult, pharmacological antihypertensive therapy seems fundamental to keep BP under control and protect target organs (13).

Several pieces of evidence suggest that combination therapy is required in most obese hypertensive (15) and agents that block the renin-angiotensin system may be especially beneficial (16-20).

Nevertheless current guidelines do not provide specific recommendations for the treatment of hypertension in obesity. In addition some therapeutic issues have not been assessed, such as the influence of obese patient heterogeneity (21), which may modulate blood pressure, metabolic disorders and target organ responses to drugs differently.
Previous research from our group has previously demonstrated the influence of obesity, and specifically visceral obesity, on the prevalence of hypertension, cardiovascular risk factors and target organ damage $(3,9)$. Moreover, clinical data obtained from our outpatients showed the benefits of specific antihypertensive drugs and the independent influence of weight reduction in terms of adequate BP control in obese hypertensive patients $(22,23)$.

In this study, we aimed at evaluating the influences of obesity, as well as fat distribution patterns, on blood pressure and target organ response upon pharmacological antihypertensive treatment.

\section{PATIENTS AND METHODS}

\section{Subjects}

Sixty-six hypertensive obese women $\left(\mathrm{BMI} \geq 30 \mathrm{~kg} / \mathrm{m}^{2}\right)$ were enrolled in this study. Most of them were on antihypertensive medication and, before the study entry, a washout period of 12 weeks was initiated for those on ACE-inhibitors and a minimum 4-week washout period for all other antihypertensive drugs.

$\mathrm{BP}$ was recorded in a sitting position using a mercury sphygmomanometer. A 12-cm wide cuff was used and corrections for brachial circumference were made accordingly. Hypertension was defined as systolic blood pressure $(\mathrm{SBP}) \geq 140$ and/or diastolic blood pressure (DBP) $\geq 90 \mathrm{mmHg}$ for two consecutive readings one week apart, and the mean of the two readings was used.

Over the washout period, 11 patients were excluded, mainly due to symptoms related to drug withdraw- 
al; 55 patients entered the study protocol, 6 were eliminated because of drug related side effects (leg edema and cough) and 49 women with a body mass index (BMI) between 30.8 to $48.8 \mathrm{~kg} / \mathrm{m}^{2}$ were treated during 24 weeks. Twenty-two patients $(44.9 \%)$ had stage 1 hypertension and the remaining ones were in stage 2 .

Thirty-seven normotensive obese women, with a BMI between 30.4 and $50.0 \mathrm{~kg} / \mathrm{m}^{2}$ and BP below $140 / 90 \mathrm{mmHg}$, were selected for comparison with the hypertensive obese group.

Hypertensive and normotensive obese women were designated into groups according to the fat distribution, based on standard waist/hip ratio measurements (24).

Waist-to-hip ratio (WHR) has been largely used in population studies and shown to be a better predictive anthropometric parameter in assessing cardiovascular risk (25-28). Also, WHR has been proven to be better than waist circumference in its association with visceral fat measured by tomography in selected obese populations (29).

The classical cutoff value of 0.85 for WHR in women was not used in this study. Instead, a cutoff of 0.888 derived from the first quartile of the mean for the hypertensive obese group was used. As a result, normotensive and hypertensive groups were respectively divided into subgroups of 19 and 37 with troncular fat distribution (troncular obese subjects), and 18 and 12 with peripheral adiposity (peripheral obese subjects).

This approach is warranted, since it has been demonstrated a continuous and progressive risk according to increasing levels of WHR in groups of individuals with different body mass index levels, including those with BMI higher than $30 \mathrm{~kg} / \mathrm{m}^{2}(26)$. Moreover, the wide differences between South American, North American, European and Asian populations might influence the fat deposition pattern and therefore the classical cutoff value may not be the best choice. Recently, a large worldwide population study, demonstrated that the waist-to-hip ratio was highest in South American and Middle East American populations, when compared with other parts (27).

Our approach is also supported by other studies which used higher anthropometrics threshold values (including WHR) for obese populations, determined from general population percentiles (30-32).

\section{Exclusion criteria}

Patients with SBP $\geq 180 \mathrm{mmHg}$ and/or DBP $\geq 110 \mathrm{mmHg}$ prior to or during the washout period; $\mathrm{BMI} \geq 50 \mathrm{~kg} / \mathrm{m}^{2}$; diagnosis of secondary hypertension; diabetes; coronary heart disease; heart and renal failure; and those who used drugs that might interfere with BP control, such as hormone replacement therapy, appetite suppressants, anti-inflammatory agents, etc were excluded from the study.

This protocol met the requirements of the local Ethics Committee and all participants signed a written informed consent before being included.

\section{Biochemical assessment}

Serum glucose, insulin (immunoassay-micro particles, AXSYM-Abbott, normal range: 2.5-25.0 mU/1), norepinephrine (high performance liquid chromatography, normal range: $144-352 \mathrm{pg} / \mathrm{ml}$; ) and microalbuminuria levels (in overnight urine; imunno-turbidimetry method - Cobas Mira Plus, Roche, normal values: < $15 \mu \mathrm{g} /$ minute) were measured at the washout period and after 24 weeks of treatment.

\section{Echocardiographic Evaluation}

Cardiac structure was evaluated by an M-mode/twodimensional echocardiogram (Esaote Biomedica model SIM 5000). Septum thickness (SPT), posterior wall thickness (PWT) and left ventricular diastolic diameter (LVDD) were obtained by ASE criteria. Left ventricular mass (LVM) was calculated according to Devereux formula (33) indexed by the exponential height $\left(\mathrm{h}^{2.7}\right)$ (normal $<46.7 \mathrm{~g} / \mathrm{m}^{2.7}$ ), as proposed for obese individuals (34).

\section{4-hour ABPM}

Twenty-four hour ambulatory blood pressure monitoring (ABPM) was performed using a noninvasive automatic monitor (Space Labs, model 90207). Daytime was considered as the period over which subjects were awake and went about their usual activities; nighttime was sleeping time. BP was read at 15- and 20-minute intervals all over day and night times. Mean daytime and nocturnal SBP and DBP were used in the analysis.

\section{Antihypertensive treatment}

To achieve BP targets of $\mathrm{SBP}<140 \mathrm{mmHg}$ and $\mathrm{DBP}<$ $90 \mathrm{mmHg}$ in the 24-week follow-up period, patients entered a stepwise antihypertensive drug regimen with uptitration every 4 weeks, starting with the ACE inhibitor cilazapril, in doses ranging from $2.5 \mathrm{mg}$ to $5.0 \mathrm{mg}$ daily. Where BP targets were not achieved, of hydrochlorothi- 
azide (HCTZ) $12.5 \mathrm{mg}$ were added to the regimen and finally, as needed, 5 tol $0 \mathrm{mg}$ amlodipine was given daily.

Patients were evaluated on a monthly basis by BP readings and assessed for required adjustments to treatment. Final drug regimens were evaluated as was the mean of individual drug doses taken during the 24 weeks.

All patients were recommended dietary changes and no pharmacological therapy for weight reduction was allowed.

\section{Statistical Analysis}

Data was stored in Excel software and analyzed by Jandel Scientific/Sigma Stat and SPSS 8.0 programs. Mean \pm 1 SD was used for continuous variables and median for microalbuminuria. Comparative analysis between groups was performed using Student's $t$ test and ANOVA. For non-continuous variables, MannWhitney and Kruskal-Wallis tests were used. Covariance test was used for age and BMI adjustments in comparisons between hypertensive and normotensive patients. Pre- and post-treatment analyses were performed using paired $t$ test and compared in terms of percentage differences by Student's $t$ test (95\%CI). Variance analysis for repeated measurements reinforced those previous analyses. The random effects model was used to evaluate the association between blood pressure changes and antihypertensive agent in selected responses. P-values lower than 0.05 were considered significant.

\section{RESULTS}

\section{Normotensive and hypertensive obese subjects}

Normotensive and hypertensive obese groups differed significantly in age $(39.8 \pm 11.6$ vs $46.6 \pm 10.4 \mathrm{vs}, \mathrm{p}<0.05)$ and BMI $\left(39.3 \pm 9.0\right.$ vs $\left.35.8 \pm 4.7 \mathrm{~kg} / \mathrm{m}^{2}, \mathrm{p}<0.05\right)$. As expected, BP parameters and cardiorenal involvement were significantly higher in the hypertensive obese subjects after adjustments for these variables (Table 1).

Table 1. Office-BP, ABPM and target organ variables in hypertensive obese subjcets before and after treatment and in normotensive obese subjects.

\begin{tabular}{|c|c|c|c|c|}
\hline & $\begin{array}{c}\text { Normotensive } \\
\text { obese }\end{array}$ & \multicolumn{3}{|c|}{ Hypertensive obese } \\
\hline & & Baseline & 24 week & $\%$; baseline - 24 w \\
\hline $\mathrm{N}$ & 36 & 49 & 49 & \\
\hline $\mathrm{BMI}\left(\mathrm{kg} / \mathrm{m}^{2}\right)$ & $39,3 \pm 9,0$ & $35,8 \pm 4,7^{\star *} 1$ & $35,2 \pm 4,7^{\& 1 \& 2}$ & $-1,4 \pm 4,1$ \\
\hline O-SBP (mmHg) & $122,1 \pm 9,4$ & $155,7 \pm 13,4^{* 1}$ & $132,7 \pm 12,2^{* 1 * 2}$ & $-23,2 \pm 14,5$ \\
\hline O-DBP (mmHg) & $78,5 \pm 6,1$ & $99,5 \pm 7,0^{* 1}$ & $84,9 \pm 10,1^{* 1 * 2}$ & $-14,6 \pm 10,5$ \\
\hline SBP-day (mmHg) & $122,0 \pm 7,6$ & $154,1 \pm 16,1^{\star 1}$ & $131,8 \pm 8,1^{* 1 * 2}$ & $-22,8 \pm 15,8$ \\
\hline DBP-day (mmHg) & $76,2 \pm 7,2$ & $98,9 \pm 11,8^{\star 1}$ & $84,6 \pm 7,2^{* 1 * 2}$ & $-14,5 \pm 15,7$ \\
\hline SBP-night (mmHg) & $107,9 \pm 7,4$ & $138,3 \pm 17,6^{\star 1}$ & $121,7 \pm 12,7^{* 1 * 2}$ & $-17,0 \pm 14,1$ \\
\hline DBP-night (mmHg) & $62,0 \pm 6,3$ & $83,7 \pm 12,3^{* 1}$ & $72,9 \pm 8,1^{* 1 * 2}$ & $-10,9 \pm 10,4$ \\
\hline Plasma glucose (mg/dl) & $91,8 \pm 14,7$ & $100,8 \pm 10,6$ & $99,0 \pm 14,4^{* * 1}$ & $-1,98 \pm 3,1$ \\
\hline Cholesterol (mg/dl) & $201,2 \pm 35,6$ & $220,5 \pm 42,2^{* * 1}$ & $215,1 \pm 48,5$ & $-4,0 \pm 21,2$ \\
\hline Insulin (mUl/ml) & $16,4 \pm 9,5$ & $15,0 \pm 6,3$ & $18,4 \pm 7,5$ & $3,4 \pm 1,8$ \\
\hline Norepinephrine (pg/ml) & $126,2 \pm 65,5$ & $150,4 \pm 78,9$ & $180,9 \pm 63,6^{81}$ & $30,5 \pm 17,0$ \\
\hline $\operatorname{LVM}(g)$ & $135,5 \pm 26,9$ & $175,3 \pm 39,7^{* 1}$ & $161,2 \pm 36,0 * 1 \& 2$ & $-7,5 \pm 17,1$ \\
\hline LVM/h ${ }^{2,7}\left(\mathrm{~g} / \mathrm{m}^{2,7}\right)$ & $40,4 \pm 7,0$ & $53,6 \pm 12,6^{* 1}$ & $49,7 \pm 11,3^{* 1 \& 2}$ & $-5,2 \pm 18,5$ \\
\hline $\mathrm{SPT}(\mathrm{mm})$ & $8,9 \pm 1,2$ & $10,9 \pm 1,9^{* 1}$ & $10,8 \pm 1,8^{* 1}$ & $-0,6 \pm 16,6$ \\
\hline PWT (mm) & $9,0 \pm 1,3$ & $10,8 \pm 1,7^{\star 1}$ & $10,2 \pm 1,6^{* 1 * * 2}$ & $-4,0 \pm 13,7$ \\
\hline LVDD (mm) & $46,2 \pm 4,3$ & $45,3 \pm 3,9$ & $44,4 \pm 4,1$ & $-1,6 \pm 7,5$ \\
\hline Micro (mcg/min) & $6,4(1,9 / 37,4)$ & $35,9(7,6 / 68,1)^{* * 1}$ & $8,7(4,5 / 20,3)^{\star 2}$ & $-64,3(-88,9 /-25,9)$ \\
\hline
\end{tabular}

$\mathrm{O}=$ office /SBP/DBP; LVM= left ventricular mass; LVM/h 2,7= corrected for height2,7; SPT=septum; PWT= posterior wall thickness; LVDD = left ventricular diastolic diameter; ${ }^{*} p<0,0001$; \& $p<0,01$; ${ }^{\star *} p<0,05$; $p$ - 1vs obese normotensive subjects and $\mathrm{p}-2 \mathrm{vs}$ obese hypertensive subjective at baseline. 
Table 2 shows baseline demographic and clinical characteristics for each subgroup of normotensive and hypertensive patients. The subgroup analysis shows, as expected, significant differences in WHR. Despite nonsignificant differences of BP and cardiorenal parameters between the subgroups, a trend toward higher BP levels and cardiorenal impairment from peripheral normotensive obese to troncular hypertensive obese subjects was observed.

Non-significant absolute higher values for nocturnal BP levels and a smaller nocturnal SBP dipping $(\mathrm{p}<0.05)$ were noted in troncular hypertensive obese subjects. This nocturnal BP pattern might have influenced the heart structure, since inverse correlations of nocturnal SBP dipping with septum thickness $\left(\mathrm{r}^{2}-0.30\right.$, $\mathrm{p}<0.04)$, left ventricular wall thickness $\left(\mathrm{r}^{2}-0.29, \mathrm{p}<0.04\right)$ and left ventricular mass/height ${ }^{2,7}\left(\mathrm{r}^{2}-0.33, \mathrm{p}<0.03\right)$ were noted in hypertensive obese subjects.

In addition, in multiple regression analyses, target organ parameters were predicted by nocturnal SBP (septum and LV wall thickness, $\mathrm{p}<0.0001$, coefficient $0.05+0.01$ ) and by nocturnal DBP (microalbuminuria, $\mathrm{p}<0.01$; coefficient $20.9+8.0$ ).

\section{Antihypertensive regimens}

At the end of the 24th week 9 patients were still on cilazapril alone $(18.4 \%), 13$ were receiving cilazapril plus HCTZ (26.5\%) and, for the remaining 27 patients (55.1\%), the triple therapy with cilazapril plus HCTZ plus amlodipine was required.

Drug regimens were not significantly different between the troncular and peripheral hypertensive obese women: cilazapril alone ( $16.2 \%$ vs $25 \%)$; cilazapril + HCTZ (27\% vs $25 \%$ ) and cilazapril + HCTZ + amlodipine $(56.7 \%$ vs $50 \%)$, nor were the mean of daily doses at the 24th week: cilazapril: $4.9 \pm 0.41$ vs $5.0 \pm 0 \mathrm{mg} /$ day; HCTZ: $12.5 \pm 0$ vs $12.5 \pm 0 \mathrm{mg} /$ day and amlodipine: $7.9 \pm 2.5$ vs $8.3 \pm 2.6 \mathrm{mg} /$ day. Antihypertensive treatment was generally well tolerated and the drugrelated adverse side effect profile did not differ from that previously described for these medications.

\section{Office blood pressure and ABPM responses to antihypertensive treatment}

Upon 24 weeks of antihypertensive therapy, hypertensive obese subjects had their BP levels well controlled for both office and ABPM measurements, although final levels were still higher than those found in normotensive obese subjcets (Table 1 ).

Over ABPM daytime-SBP/DBP < $135 / 85 \mathrm{mmHg}$ was observed in $24 \mathrm{HTOB}$ patients $(40.8 \%)$ and in a further 13 patients $(26.5 \%)$, levels were lower than $140 / 90 \mathrm{mmHg}$. Ten patients had their final BP monitored between 140-149 and 90-99 $\mathrm{mmHg}$ and in 7

Table 2. Baseline characteristics of normotensive $(n=37)$ and hypertensive obese $(n=49)$ with relation to body fat distribution.

\begin{tabular}{|c|c|c|c|c|}
\hline & \multicolumn{2}{|c|}{ Normotensive obese } & \multicolumn{2}{|c|}{ Hypertensive obese } \\
\hline & $\begin{array}{l}\text { Peripheral } \\
\qquad(\mathrm{N}=18)\end{array}$ & $\begin{array}{c}\text { Troncular } \\
(\mathrm{N}=19)\end{array}$ & $\begin{array}{l}\text { Peripheral } \\
\qquad(\mathrm{N}=12)\end{array}$ & $\begin{array}{l}\text { Troncular } \\
(\mathrm{N}=37)\end{array}$ \\
\hline Age (years) & $41.4 \pm 10.9$ & $38.3 \pm 12.4$ & $46.7 \pm 9.3$ & $46.6 \pm 10.8$ \\
\hline Weight (kg) & $90.7 \pm 15.5$ & $94.5 \pm 12.1$ & $87.9 \pm 19.6$ & $85.8 \pm 11.5$ \\
\hline $\mathrm{BMI}\left(\mathrm{kg} / \mathrm{m}^{2}\right)$ & $38,9 \pm 5.9$ & $37.4 \pm 4.7$ & $36.2 \pm 6.1$ & $35.7 \pm 4.2$ \\
\hline Waist/Hip Ratio & $0.85 \pm 0.02$ & $0.95 \pm 0.05^{*}$ & $0.85 \pm 0.03$ & $0.96 \pm 0.05^{*}$ \\
\hline O-SBP (mmHg) & $120.3 \pm 10.1$ & $124.5 \pm 9.8$ & $155.5 \pm 15.2$ & $156.4 \pm 13.3$ \\
\hline O-DBP (mmHg) & $77.9 \pm 6.4$ & $80.2 \pm 6.4$ & $99.9 \pm 7.1$ & $99.6 \pm 7.1$ \\
\hline SBP-day (mmHg) & $120.8 \pm 8.2$ & $122.9 \pm 6.9$ & $151.6 \pm 14.0$ & $155.0 \pm 17.5$ \\
\hline DBP-day (mmHg) & $76.2 \pm 5.7$ & $76.3 \pm 8.3$ & $94.9 \pm 9.5$ & $100.2 \pm 12.3$ \\
\hline SBP-night (mmHg) & $106.5 \pm 5.8$ & $109.3 \pm 8.5$ & $132.1 \pm 14.7$ & $140.3 \pm 18.2$ \\
\hline DBP-night (mmHg) & $61.5 \pm 5.1$ & $62.6 \pm 7.3$ & $83.7 \pm 12.3$ & $85.5 \pm 12.8$ \\
\hline $\mathrm{LVM} / \mathrm{h}^{2.7}\left(\mathrm{~g} / \mathrm{m}^{2.7}\right)$ & $40.6 \pm 7.8$ & $40.2 \pm 6.4$ & $50.2 \pm 5.6$ & $54.7 \pm 14.1$ \\
\hline Microalbuminuria ( $\mu \mathrm{g} / \mathrm{min})$ & $3.2(1.8 / 29.7)$ & $10.7(4.6 / 43.1)$ & $15(7.6 / 66.6)$ & $36(6.1 / 96.1)$ \\
\hline
\end{tabular}

$\mathrm{BMI}=$ body mass index; $\mathrm{O}=$ office $/ \mathrm{SBP} / \mathrm{DBP} ; \mathrm{LVM} / \mathrm{h}^{2,7}=$ left ventricular mass corrected for height $2,7 \mathrm{p}$ values are given for comparison between troncular and peripheral obesity.

${ }^{*} \mathrm{p}<0,001$. 
(14.2\%) the BP decrease was greater than $10 \%$. Only 2 patients had their final BP recorded higher than $150 / 100 \mathrm{mmHg}$.

Office BP and daytime/nocturnal ABPM values were similarly lower in both hypertensive obese subgroups after treatment (Table 3 ). However, greater decreases in night-time pressure, mainly for SBP $(-19.3 \pm 14.3$ vs $-10.4 \pm 11.5 \mathrm{mmHg}, \mathrm{p}<0.05)$, were observed in the troncular hypertensive obese subjects. These findings were confirmed after performing variance analysis using repeated measurements (Figure 1). Despite BP target has been achieved in both hypertensive obese subgroups (SBP: 130-135 and DBP: $80-85 \mathrm{mmHg}$ ), the differences against normotensive subgroups persisted, particularly for nocturnal values.

\section{Body weight changes}

Despite dietary recommendations (1200 to $1600 \mathrm{kcal} /$ day), there was only a slight body weight loss in most patients (Table 1), corresponding to less than 2\% BMI reduction in both subgroups (troncular obese subjects: $-1.4 \pm 4.3 \%$; peripheral obese subjects: $-1.3 \pm 3.6 \%)$. Ten patients $(8$ with troncular and 2 with peripheral obesi- ty) had a weight loss greater than $5 \%$. BP responses in these patients were somewhat greater, although nonsignificant, when measured in the office but not over ABPM. Also, changes in LVM/height ${ }^{2.7}$ did not differ from that observed in patients with weight loss $<5 \%$.

\section{Biochemical parameters}

Baseline plasma glucose and insulin levels were similar in both obese hypertensive subgroups and did not change significantly during antihypertensive treatment (Table 1). Baseline plasma norepinephrine levels were also similar, increasing significantly during antihypertensive treatment in both obese subgroups, and that was probably related to the use of a calcium channel blocker, but they still remained within the normal range.

No significant correlations of those biochemical parameters were found for either BP or target organ damage at baseline or during treatment.

\section{Target organ responses}

After 24 weeks, there was a slight decrease in LVM in the hypertensive obese group $(\mathrm{p}<0.01 ;-7.5 \pm 17.1 \%)$

Table 3. Office-BP, ABPM and target organ variables in hypertensive obese subjects with relation to fat distribution, before and after treatment.

\begin{tabular}{|c|c|c|c|c|}
\hline \multirow{2}{*}{ Blood pressure parameters } & \multicolumn{2}{|c|}{ Troncular obesity } & \multicolumn{2}{|c|}{ Peripheral obesity } \\
\hline & Washout & 24 weeks & Washout & 24 weeks \\
\hline N & 37 & 37 & 12 & 12 \\
\hline O-SBP (mmHg) & $156.4 \pm 13.3$ & $133.4 \pm 13.3^{*}$ & $155.5 \pm 15.2$ & $131.5 \pm 7.7^{*}$ \\
\hline O-DBP (mmHg) & $99.6 \pm 7.1$ & $85.5 \pm 10.9^{2}$ & $99.9 \pm 7.1$ & $83.8 \pm 6.9^{*}$ \\
\hline SBP-day (mmHg) & $155.4 \pm 17.6$ & $132.9 \pm 8.2$ & $151.6 \pm 14.0$ & $128.0 \pm 7.1^{*}$ \\
\hline DBP-day (mmHg) & $100.4 \pm 12.5$ & $83.0 \pm 6.5$ & $94.9 \pm 9.5$ & $80.0 \pm 7.6$ \\
\hline SBP-night (mmHg) & $140.7 \pm 18.3$ & $121.4 \pm 13.2$ & $132.1 \pm 14.7$ & $121.7 \pm 11.8$ \\
\hline DBP-night (mmHg) & $85.5 \pm 13.0$ & $73.3 \pm 8.5$ & $78.5 \pm 9.4$ & $71.3 \pm 6.8^{8}$ \\
\hline \multicolumn{5}{|c|}{ Ecocardiographic parameters } \\
\hline LVM (g) & $178.6 \pm 93.7$ & $165.8 \pm 39.5$ & $165.1 \pm 22.3$ & $153.7 \pm 20.1$ \\
\hline LVM $/ h^{2.7}\left(\mathrm{~g} / \mathrm{m}^{2.7}\right)$ & $54.7 \pm 14.1$ & $50.7 \pm 12.3^{* \prime}$ & $50.2 \pm 5.6$ & $46.9 \pm 7.1$ \\
\hline SPT (mm) & $11.1 \pm 2.1$ & $11.1 \pm 1.9$ & $10.5 \pm 1.4$ & $10.0 \pm 1.1$ \\
\hline PWT (mm) & $10.9 \pm 1.8$ & $10.3 \pm 1.7^{* *}$ & $10.2 \pm 0.97$ & $9.4 \pm 1.2$ \\
\hline LVDD (mm) & $45.3 \pm 4.2$ & $44.5 \pm 4.3$ & $45.7 \pm 3.0$ & $44.8 \pm 3.4$ \\
\hline \multicolumn{5}{|c|}{ Renal parameter } \\
\hline Microlbuminuria (mcg/min) & $36.5(6.1 / 96.1)$ & $9.4(5.1 / 45.1)^{*}$ & $15.0(7.6 / 66.8)$ & $7.7(38 / 14.1)^{8}$ \\
\hline
\end{tabular}

$\mathrm{O}=$ office $/ \mathrm{SBP} / \mathrm{DBP} ; \mathrm{LVM}=$ left ventricular mass; LVM/h ${ }^{2.7}=$ corrected for height 2.7 ; SPT= septum; PWT= posterior wall thickness; LVDD = left ventricular diastolic diameter.

$p$ values are given for paired T test between baseline and 24-week treatment periods in hypertensive subgroups; ${ }^{*} p<0,001$; $\& p<0,01 ; " * p<0,05$ 


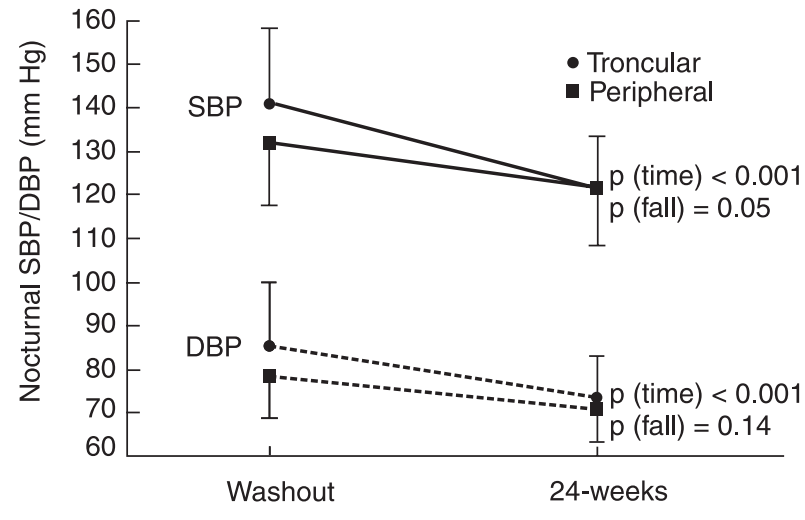

Figure 1. Nocturnal systolic and diastolic blood pressures changes after 24-week therapy in obese subgroups; $\mathrm{p}$ time values are given between washout and 24-week period; $p$ fall values are given between troncular and peripheral obesity subgroups.

and post-treatment values were still significantly higher than in normotensive obese patients (Table 4).

Upon subgroup analysis (Table 3), a slight and similar decrease of LVM / LVM $/ \mathrm{h}^{2.7}$ was observed again for both troncular: $-7.4 \% /-5.0 \%$ and peripheral: $-8.0 /-5.8 \%$ obese subjects, mainly due to PWT reduction. $\mathrm{LVM} / \mathrm{h}^{2.7}$ values, especially for the troncular obese women, remained higher than the cutoff value for obese subjects $\left(46.7 \mathrm{~g} / \mathrm{m}^{2.7}\right)$ and also significantly higher than what was seen for normotensive obese subjects (Figure 2- Panel A).

Microalbuminuria, on the other hand, decreased significantly in the group as a whole $(\mathrm{p}<0.0001 ;-64.3 \%)$ and post-treatment levels were almost similar to those of normotensive obese subjects (Table 1). In both subgroups, UAE was greatly and similarly reduced and post-treatment levels also matched those for normotensive subjects (Table 3; Figure 2- Panel B).

Both cardiac structural parameters and UAE changes occurred parallel to the drug dosages and consequent BP reductions. Therefore, as for cilazapril, cilazapril + hydrochlorothiazide and cilazapril + hydrochlorothiazide + amlodipine, reductions in BP were, respectively, daytime: $-10.4 \pm 6.9 /-6.8 \pm 4.7 ;-15.5 \pm 9.4 /-9.1 \pm 6.0 ;-31.0 \pm 16.1 /$ $-20.2 \pm 11.6 \mathrm{mmHg} ; \quad$ night-time: $-1.2 \pm 8.2 /-0.62 \pm 7.6$; $-16.8 \pm 9.5 /-11.2 \pm 7.3 ;-22.7 \pm 14.3 /-14.4 \pm 10.8 \mathrm{mmHg}$, which were accompanied by proportional changes in $\mathrm{LVM} / \mathrm{h}^{2.7}:-1.23 \pm 26.3 ;-4.9 \pm 13.7 ;-6.8 \pm 18.2 \%$ and UAE: $-37.2[-15 /-87.9] ; \quad-52.0[-22.3 /-85.8] ;-58.8$ $[-25.9 /-88.7] \mu \mathrm{g} / \mathrm{min}$. WHR was similar among the three drug groups, which reinforces the independence between body fat distribution and antihypertensive demands.
80

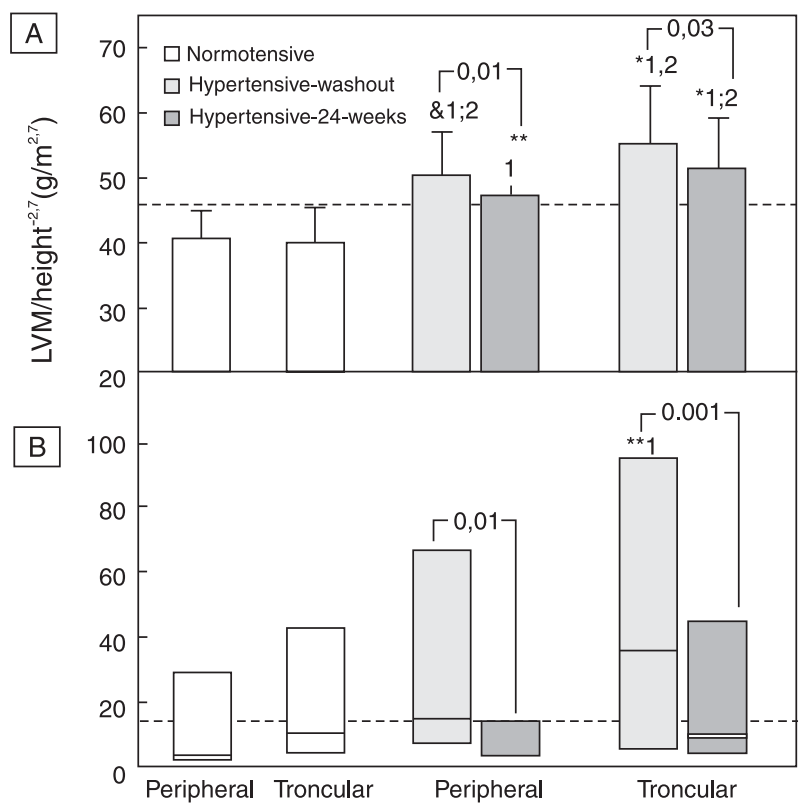

Figure 2. Left ventricular mass indexed to $2,7(\mathrm{~A})$ and microalbuminuria (B) in normotensive and hypertensive obese individuals; $\mathrm{p}-1$ vs peripheral and $\mathrm{p}-2 \mathrm{vs}$ troncular normotensive obese individuals; $p$ * $<0.0001$; \& $p<0.01$; ** $p<0.05$; in the bars- between washout and 24 weeks

Table 4 shows the results of random effects analysis, which evaluated the impact of $\mathrm{BP}$ variables and drugs on echocardiography and microalbuminuria changes. Both selection methods (forward or backward) showed that changes in LVM parameters were directly associated with nocturnal BP reduction, BMI and cilazapril doses. The change in microalbuminuria was associated with daytime SBP changes. These findings were confirmed when central obese hypertensive subjects were separately analyzed.

\section{DISCUSSION}

Failure to control blood pressure in obesity is usually attributed to persistent overweight and to the neurohumoral-activated mechanisms $(2,10,35)$, particularly in patients with troncular obesity who are in general more insulin resistant than those with peripheral obesity. Therefore greater difficulties to control blood pressure and more antihypertensive agent requirements might be antecipated for patients with troncular obesity.

However, our data does not favor this assumption, since we observed a similar degree of decreased blood pressure using similar amounts of antihypertensive 
Table 4. Random effects model for drug and blood pressure parameters with relation to echocardiography and albuminuria.

\begin{tabular}{|c|c|c|c|c|}
\hline \multirow{3}{*}{ Selection } & \multicolumn{2}{|c|}{$\mathrm{LVM} / \mathrm{h}^{2,7}{ }_{1-2}$} & \multicolumn{2}{|c|}{ Microalbuminuria $(\log )_{1-2}$} \\
\hline & \multicolumn{2}{|c|}{ Backward } & \multicolumn{2}{|c|}{ Backward/Forward } \\
\hline & Coefficient & $p$ & Coefficient & $\mathrm{p}$ \\
\hline Cilazapril & $-0.03 \pm 0.017$ & 0.05 & --- & \\
\hline Amlodipine & $0.01 \pm 0.004$ & 0.02 & --- & \\
\hline HCTZ & --- & & --- & \\
\hline SBP-day $_{1-2}$ & --- & & $0.03 \pm 0.007$ & $<0.0001$ \\
\hline SBP-night $_{1-2}$ & --- & & --- & \\
\hline DBP-night $_{1-2}$ & $0.30 \pm 0.08$ & 0.0008 & --- & \\
\hline $\mathrm{BMI}_{1-2}$ & $0.65 \pm 0.28$ & 0.02 & --- & \\
\hline Selection & Forv & & & \\
\hline SBP-night $_{1-2}$ & $0.24 \pm 0.05$ & $<0.0001$ & & \\
\hline $\mathrm{BMI}_{1-2}$ & $0.59 \pm 0.28$ & 0.04 & & \\
\hline
\end{tabular}

LVM/h ${ }^{2,7}=$ left ventricular mass corrected for height ${ }^{2.7}$ HCTZ= hydroclorthiazide; 1-2= washout - 24 weeks

medications in both troncular and peripheral obese hypertensive women in 24 weeks of follow-up. Moreover, the troncular obese patients experienced a more significant decrease in their nocturnal pressures.

Therefore, our findings showed that antihypertensive therapy was effective in providing a satisfactory $\mathrm{BP}$ control regardless of adiposity distribution.

It should be emphasized that both groups did not present a significant weight loss which would be of some benefit to BP or neurohumoral control $(10,36)$. Weight maintenance and the supposed non-mobilization of visceral adiposity may even explain differences in pressure levels between treated HTOB and NTOB controls. In spite of similar $\mathrm{W} / \mathrm{H}$ means between each subgroup (troncular and peripheral obesity) of normotensive and hypertensive obese subjects, it is likely that HTOB present a greater accumulation of visceral adiposity that could be best detected by more accurate methods.

Some data point to visceral adiposity mobilization rather than weight loss as implicated in pressure and metabolic improvement in obese people (36). However, refractoriness towards weight loss renders the adiposity mobilization little realistic, especially in women (37), thus strengthening maximization of antihypertensive therapy.

In this aspect, it is important to note that in order to reach the blood pressure target, the majority of patients needed treatment with 2 or 3 drugs and monotherapy was effective for only $18.4 \%$. Mean number of medications per patient in our study was 2.4 , and it was similar between women with troncular or peripheral obesity. These observations add to those in several clinical trials on hypertension, which have shown the requirement of 2 or more antihypertensive agents to obtain an optimal BP control, particularly in high risk groups (38-40) and in more recent data from obese-hypertensive populations (15), stressing the similarity of antihypertensive requirements in obesity, a condition commonly linked to antihypertensive therapeutic failure $(15,40)$, to that of high risk patients.

The drug regimen chosen for this study was based in part on the obesity-hypertension pathophysiology, where the advantages of the renin-angiotensin system blockade have been shown, $(8,16,19,20,41)$ and also because it has been widely demonstrated that ACE-inhibitor, diuretic and calcium channel blocker combinations adds efficacy to treatment and thus help to reach the BP targets.

Despite the antihypertensive efficacy, benefits to cardiac structural changes were far less than we expected. The reduction in LVM was on average only $14 \mathrm{~g}$ (7.5\%) and, after correction, LVM was still above the cutoff $\left(46.7 \mathrm{~g} / \mathrm{m}^{2.7}\right)$ (34). Similar observations were made for troncular and peripheral obese people, who respectively presented decreases in LVM of $7.5 \%$ and $8.6 \%$, reaching final means of 50.7 and $46.9 \mathrm{~g} / \mathrm{m}^{2.7}$.

Since in this study most of the required conditions that contribute to LVM regression in the hypertensive 
were present (42), e.g., appropriate decrease in BP, length of treatment, type of antihypertensive agents and previous left ventricular hypertrophy, it is reasonable to suppose that the absence of a significant decrease in body weight, which is an important goal for cardiac reversion $(11,12)$, was responsible for the maintenance of increased LVM.

In MacMahon's study, considerable weight reduction explained $25 \%$ of LVM variation (11). More recently, Himeno (12), evaluating normotensive and hypertensive obese individuals with moderate weight losses, observed decreases in LVM of 9 and 12\% without BP decrease in normotensives.

Another study (43) compared two regimens in hypertensive obese subjects, amlodipine with and without diet intervention, showed LVM decrease of $23.2 \%$ and $14.7 \%$, respectively. The $8.5 \%$ difference was apparently due to a $10 \%$ weight loss. Similarresults were obtained using captopril with and without diet intervention (44).

Previous data from our group and others $(45,46)$ also stressed the benefits of weight reduction upon pharmacologic therapy on LVM regression in obese hypertensive patients, regardless of BP control.

This data shows that about $10 \%$ of LVM decrease could have been added if a moderate weight loss had been achieved in this study.

It is clear that antihypertensive therapy alone is not able to properly reverse LVM in obese patients. Even with 2 to 3 drugs, no more than 10\% decrease was obtained. In the group with monotherapy, practically no LVM reversion was noted, coincidently with lack of nocturnal pressure dip, which was predictive of reversion cardiac mass in this study.

Considering the obese subgroups, there were no differences in cardiac structural changes, BP control, drug intake and treatment length, as well as in weight loss. However, since troncular obese women had somewhat higher BP and LVM levels at baseline and experienced greater nocturnal dips in pressures, a greater LVM decrease should therefore be expected in those patients. This was not the case, which might be due to maintenance of visceral adiposity in this subgroup.

Also, at 24 weeks, LVM remained greater than in normotensive obese subgroups. The persistence of an unestimated visceral adiposity accumulation in treated hypertensive obese subjects in this study, as well as higher, although controlled, BP levels, could also explain cardiac differences between treated patients and normotensive obese subjects. This observation is in keeping with an early trial, likewise studying treated and controlled hypertensive patients, which has shown, after 2.9 years, similar LVM differences when compared to normotensive controls (47).

Although we were unable to demonstrate any correlations of measured biochemical parameters in our study, this data strengthens the participation of nonhemodynamic mechanisms (norepinephrine, leptin, insulin, etc) in left ventricular hypertrophy of obese hypertensive patients, particularly in the troncular obese subgroup, and is in accordance with recently published data that demonstrates and independent association of metabolic syndrome, expression of visceral fat (48) and LVM structure changes (49).

The impact of BP control on kidney damage was very successful in our treated hypertensive obese women, who had their microalbuminuria normalized and matching normotensive subjects. This data concurs with a previous study $(50)$, in which microalbuminuria reduction occurred parallel to the degree of $\mathrm{BP}$ reduction and was particularly influenced by daytime SBP. Therefore, in contrast to the cardiac repercussions, proper blood pressure control overcame the eventual harmful renal consequences of weight maintenance in obese hypertensive individuals (51). Of course, we cannot overlook the impact of the chosen antihypertensive regimen on kidney responses, as it is known from ACE inhibitors benefits towards glomerular function and their enhanced efficacy when associated with diuretics and calcium channel blockers.

Albuminuria responses through decreased BP were significant and similar when both obese hypertensive subgroups were considered and the benefits achieved were even greater for troncular obese patients, considering their pretreatment albuminuria level ranges.

In the light of these results, requirements of narrower target BP levels in obese individuals, similarly to those of diabetic patients, may be required in view of the potentially greater renal damage in this population, especially the visceral obese people, whose renal hemodynamics seem to be particularly impaired (4).

These results denoted that target organ responses, upon blood pressure control, do not occur necessarily in a parallel fashion, which reinforces the importance of controlling each organ response separately and normalizing other risk factors. This concurs with the current concept that antihypertensive treatment should be titrat- 
ed to blood pressure reduction and also to target organ protection (52), which may be evaluated previously and during antihypertensive treatment, especially in high risk groups, in order to achieve a global cardiovascular risk reduction.

In conclusion, our study showed that treatment of hypertensive obese women, in the absence of appropriate weight loss, required mostly an antihypertensive drug combination, and this requirement was not mediated by the type of obesity to achieve the same antihypertensive efficacy. Troncular obese patients experienced an even greater decrease in previously exacerbated nocturnal blood pressures. The achievement of a satisfactory BP range was also accompanied by microalbuminuria normalization, which was also similar in both obese subgroups. Despite the antihypertensive effectiveness, the benefits of BP control to cardiac structure were less evident and probably lesser due to the weight maintenance, especially in the troncular obese subjects, in which the left ventricle has remained hypertrophic.

Limitations of our study are the relative small sample size and the absence of men in the study. Further studies with a larger population, focusing on heterogeneous groups of obese subjects and seeking "ideal" antihypertensive combination therapies along with weight reduction programs and/or measures to revert visceral adiposity deposition, are required to establish therapeutic guidelines for this population.

\section{ACKNOWLEDGEMENTS}

Supported by "Fundação de Amparo à Pesquisa do Estado de São Paulo" (São Paulo State Research Foundation - FAPESP).

\section{REFERENCES}

1. Kannel WB, Cupples LA, Ramaswami R, Stokes III, Kreger BE, Higgins M. Regional obesity and risk of cardiovascular disease: the Framingham Study. J Clin Epidemiol. 1991; 44:183-90.

2. Mark AL, Correia M, Morgan DA, Shaffer RA, Haynes WG. State-of-the-art-lecture: obesity-induced hypertension: new concepts from the emerging biology of obesity. Hypertension. 1999; 33:537-41.

3. Carneiro G, Faria AN, Ribeiro Filho FF, Guimarães A, Ferreira $\mathrm{SR}$, Zanella MT. Influence of body fat distribution on the prevalence of arterial hypertension and other cardiovascular risk factors in obese patients. Rev Assoc Med Bras. 2003; 49:306-11.

4. Scaglione R, Ganguzza A, Corao J. Central obesity and hypertension: pathophysiologic role of renal haemodynamics and function. Int J Obes. 1995; 19:403-9.
5. Bullo M, Garcia-Lorda P, Megias I, Salas-Salvado J. Systemic inflammation, adipose tissue tumor necrosis factor and leptin expression. Obes Res. 2003; 11:525-31.

6. Chinali M, Devereux RB, Howard BV, Roman MJ, Bella JN, Liu JE. Comparison of cardiac structure and function in American Indians with and without the metabolic syndrome (the Strong Heart Study). Am J Cardiol. 2004; 93:40-4.

7. Liese AD, Hense HW, Doring A, Stieber J, Keil U. Microalbuminuria, central adiposity and hypertension in the non-diabetic urban population of the MONICA Augsburg Survey 1994/95. J Hum Hypertens. 2001; 15:799-804.

8. Rosa EC, Zanella MT, Ribeiro AB, Kohlmann JO. Visceral obesity, hypertension and cardio-renal risk: a review. Arq Bras Endocrinol Metabol. 2005; 49:196-204.

9. Ribeiro Filho FF, Rosa EC, Faria A, Lerario DG, Ferreira SR, Kohlmann $\mathrm{O}$, et al. Obesidade, hipertensão arterial e suas influências sobre a massa e função do ventrículo esquerdo. Arq Bras Endocrinol Metab. 2000; 44:64-71.

10. Masuo K, Mikani H, Ogihara T, Tuck ML. Weight reduction and pharmacologic treatment in obese hypertensives. Am J Hypertens. $2001 ; 14: 530-8$.

11. MacMahon SW, Wilcken DEL, Macdonald GJ. The effect of weight eduction on left ventricular mass: a randomized controlled trial in young, overweight hypertensive patients. $\mathrm{N}$ Engl J Med. 1986; 314:334-9.

12. Himeno E, Nishino K, Nakashima Y, Kuroiwa A, Ikeda M. Weight reduction regresses left ventricular mass regardless of blood pressure level in obese subjects. Am Heart J. 1996; 131:313-9.

13. Sharma AM, Pischon T, Engeli S, Scholze J. Choice of drug treatment for obesity-related hypertension: where is the evidence? J Hypertens. 2001; 19:667-74.

14. Aucott L, Poobalan A, Smith WC. Effects of weight loss in overweight/ obese individuals and long-term hypertension outcomes: a systematic review. Hypertension. 2005; 45:1035-41.

15. Bramlage P, Pittrow D, Wittchen HU. Hypertension in overweight and obese primary care patients is highly prevalent and poorly controlled. Am J Hypertens. 2004; 17:904-10.

16. Zanella MT, Bapista M, Costa $\mathrm{CH}$, Kohlmann NE, Kohlmann JO, Ribeiro AB. Comparative effects of captopril and chlortalidone on glucose tolerance and insulin levels in essential hypertensives. Arq Bras Cardiol. 1996; 67:47-52.

17. Reisin E, Weir MR, Fakner B, Hutchinson HG, Anzalone DA, Tuck ML. Treatment in Obese Patients with Hypertension (TROPHY) Study Group. Hypertension. 1997; 30(part1):140-5.

18. Jordan J, Engeli S, Boschmann M. Hemodinamic and metabolic responses to valsartan and atenolol in obese hypertensive patients. J Hypertens. 2005; 23:2313-8.

19. Grassi G, Seravalle G, Dell'Oro R. Comparative effects of candersartan and hydrochlortiazide on blood pressure, insulin sensitivity and sympathetic drive in obese hypertensive individuals: results of the CROSS study. J Hypertens. 2003; 21:1761-9.

20. Sugimoto K, Qi NR, Kazdova L. Telmisartan but not valsartan increases caloric expenditure and protects against weight gain and hepatic steatosis. Hypertension. 2006; 47:1003-9.

21. Desprès J-P, Lemieux I, Prud'homme D. Treatment of obesity: need to focus on high risk abdominally obese patients. BMJ. 2001; 322:716-20.

22. Cadaval RAM, Plavnik FL, Kohlmann NE, Kohlmann JO, Ribeiro AB, Zanella MT. Open comparative study of the effects of amlodipine and propanolol on insulin sensitivity in hypertensive patients with android obesity. Eur J Clin Res. 1996; 8:289-98.

23. Faria AN, Ribeiro Filho FF, Kohlmann NE, Ferreira SR, Zanella MT. Effect of sibutramine on abdominal fat mass, insulin resis- 
tance and blood pressure in obese hypertensive patients. Diabetes Obes Metab. 2005; 7:246-53.

24. van der Kooy K, Seidell JC. Techniques for the measurement of visceral fat: a practical guide. Int J Obes. 1993; 17:187-96.

25. Lapidus L, Bengtsson C, Larsson B. Distribution of adipose tissue and risk of cardiovascular disease and death: a 12 year follow-up of participants in the population study of women in Gotthenburg, Sweden. BMJ. 1984; 289:1257-61.

26. Dagenais GR, Yi Q, Mann JF, Bosch J, Pogue J, Yusuf S. Prognostic impact of body weight and abdominal obesity in women and men with cardiovascular disease. Am Heart J. 2005; 149:54-60.

27. Yusuf S, Hawken S, Ôunpuu S, Bautista L, Franzosi MG, Commerford $P$ et al, on behalf the INTERHEART Study Investigators. Obesity and the risk of myocardial infarction in 27000 participants from 52 countries: a case - control study. Lancet. 2005; 366:1640-9.

28. Snijder MB, Zimmet PZ, Visser M. Independent and opposite associations of waist and hip circumferences with diabetes, hypertension and dyslipidemia: the AusDiab Study. Int J Obes Relat Metab Disord. 2004; 28:402-9.

29. Després JP, Prud'homme D, Pouliot MC, Tremblay A, Bouchard C. Estimation of deep abdominal adipose-tissue accumulation from simple anthropometric measurements in men. Am J Clin Nutr. 1991; 54:471-7.

30. Vanhala MJ, Pitkajarvi TK, Kumpusalo EA, Takala JK. Obesity type and clustering of insulin resistance-associated cardiovascular risk factors in middle-aged men and women. Int $\mathrm{J}$ Obes. 1998; 22:369-74

31. Rexrode KM, Carey VJ, Hepnekens $\mathrm{CH}$, Walters FE, Colditz GA, Stamper MJ, et al. Abdominal adiposity and coronary heart disease in women. JAMA. 1998; 280:1843-8.

32. Kortelainen ML, Särkioja T. Coronary atherosclerosis and myocardial hypertrophy in relation to body fat distribution in healthy women: an autopsy study on 33 violent deaths. Int $J$ Obes. 1997; 21:43-9.

33. Devereux RB, Lutas EM. Echocardiographic assessment of left ventricular hypertrophy:comparison to necropsy findings. Am J Cardiol. 1986; 57:450-8.

34. de Simone G, Daniels SR, Devereux RB, Meyer RA, Roman $\mathrm{MJ}$, de Deribis O, Alderman $\mathrm{MH}$. Left ventricular mass and body size in normotensive children and adults: assessment of allometric relations and impact of overweight. J Am Coll Cardiol. 1992; 20:1251-60.

35. Hall JE, Brands MW, Henegar JR, Shek EW. Abnormal kidney function as a cause and a consequence of obesity hypertension. Clin Exp Pharm Phys. 1998; 25:58-64.

36. Kanai H, Tokunaga K, Fujioka S, Yamashita S, Kameda-Takemura KK, Matsuzawa Y. Decrease in intra-abdominal visceral fat may reduce blood pressure in obese hypertensive women. Hypertens. 1996; 27(1):125-9.

37. Wing RR, Jeffery RW, Burton LR, Thorson C, Kuller LH, Folsom AR. Change in waist-hip ratio with weight loss and its association with change in cardiovascular risk factors. Am J Clin Nutr. 1992; 55:1086-92.

38. Cushman WC, Ford CE, Cutler JA, Margolis KL, Davis BR, Grimm RH, et al. ALLHAT Collaborative Research Group. J Clin Hypertens. 2002; 4:393-405.
39. Bakris GL. Maximizing cardiorenal benefit in the management of hypertension: achieve blood pressure goals. J Clin Hypertens. 1999; 1:141-7.

40. Modan M, Almog S, Fuchs Z, Chetrit A, Lusky A, Haskin H. Obesity, glucose intolerance, hyperinsulinemia and response to antihypertensive drugs. Hypertension. 1991; 17:565-73.

41. Zanella MT, Kohlmann Jr O, Ribeiro AB. Treatment of obesity hypertension and diabetes syndrome. Hypertension. 2001; 38:705-8.

42. Schmieder RE, Martus $P$, Klingbeil A. Reversal of left ventricular hypertrophy in essential hypertension: a meta-analysis of randomized double blind studies. JAMA. 1996; 275:1507-13.

43. Ruvolo G, Greco E, Speziale G, Di Natae M, Marino B. Effetti sulla massa ventricolare sinistra del tratamento comn amlodipina e dietoterapia in pazienti obesi affetti da ipertensione arteriosa. Minerva Cardioangiol. 1994; 42:289-92.

44. Barzizza F, Magnani L, Crea G, Richichi L. Regression of left ventricular hypertrophy in obese hypertensive patients treated with diet and pharmacologic therapy. G Ital Cardiol. 1992; 22:453-7.

45. Faria AN, Ribeiro Filho FF, Lerario DD, Kohlmann NE, Ferreira SR, Zanella MT. Effects of sibutramine on the treatment of obesity in patients with arterial hypertension. Arq Bras Cardiol. 2002; 78:172-80.

46. Wirth A, Scholze J, Sharma AM, Matiba B, Boenner G. Redu ced left ventricular mass after treatment of obese patients with sibutramine : An echocardiographic multicentre study. Diabetes Obes Metab. 2006; 8:674-81.

47. Schillaci G, Verdecchia P, de Simone G, Sacehi N, Bruni B, Benemio $G$ et al. Persistance of increased left ventricular mass despite optimal blood pressure control in hypertens. Ital Heart J. 2000; 1:354-60.

48. Ribeiro Filho FF, Mariosa LS, Ferreira SR, Zanella MT. Visceral fat and metabolic syndrome: more than a simple association. Arq Bras Endocrinol Metabol. 2006; 50:230-8.

49. Mulè G, Nardi E, Cottone $S$, Cusimano $P$, Incalterra F, Ester Giandalia $\mathrm{M}$ et al. Impact of metabolic syndrome on left ventricular mass in overweight and obese hypertensive subjects. Int J Cardiol. 2007; 26

50. Bianchi S, Bigazzi R, Badari G, Campese VM. Microalbuminuria in patients with essential hypertension. Effects of several antihypertensive drugs. Am J Med. 1992; 93:525-8.

51. Praga M, Morales E. Obesity, proteinuria and progression of renal failure. Curr Opin Nephrol Hypertens. 2006; 15:481-6.

52. Redon J. Antihypertensive treatment: should it be titrated to blood pressure reduction or to target organ damage regression? Curr Opin Nephrol Hypertens. 2005; 14:448-52.

\section{Address for correspondence:}

Eduardo Cantoni Rosa, MD

Rua Harmonia 765 apto 121

05435-000 - São Paulo, SP

E-mail: eduardocantoni@uol.com.br 